\title{
De vagos y maleantes a peligrosos sociales: cuando la homosexualidad dejó de ser un delito en España (1970-1979)
}

\author{
From Vagrants and Criminals to Socially Dangerous: When \\ Homosexuality was Decriminalised in Spain (1970-1979)
}

VALENTÍN GALVÁN*

En algún rincón apartado del universo perdido en el flamear de innumerables sistemas solares, hubo una vez una estrella sobre la que animales inteligentes inventaron el conocimiento. Fue el minuto más arrogante y mentiroso de la historia universal: pero fue sólo un minuto. Tras algunos suspiros de la naturaleza, la estrella se congeló y los animales inteligentes murieron.

Nietzsche

\begin{abstract}
Resumen: A partir de la Ley de Peligrosidad y Rehabilitación Social (1970) se inició el movimiento social de liberación de gays y lesbianas. Desde la Agrupación Homosexual para la Igualdad Sexual (1972) se organizaron varios colectivos hasta aglutinarse en la Coordinadora de Frentes de Liberación Homosexual del Estado Español. En el contexto social y político de la transición lucharon junto con otros grupos marginales no sólo por la Derogación de la LPRS sino también ante la incomprensión de la mayoría de los partidos políticos marxistas, que eludieron enfrentarse a aspectos que reportaran un cambio en la sexualidad y en la institución familiar.

Palabras clave: España, LPRS, grupos marginales, transición, liberación sexual, partidos revolucionarios.
\end{abstract}

\begin{abstract}
As a result of the Ley de Peligrosidad y Rehabilitación Social of 1970 (Social Danger and Social Rehabilitation Act), the gays and lesbians liberation movement was started. From the Agrupación Homosexual para la Igualdad Sexual in 1972 (Homosexual Group for Social Equality), different groups were organised until they developed into the Coordinadora de Frentes de Liberación Homosexual del Estado Español (Homosexual Liberation Fronts Committee from Spain). In the social and political context of the Spanish transition, they, together with marginal groups, fought not only for the abolition of the above mentioned law, but also against the incomprehension of most of the marxist parties, which avoided facing changes regarding with sexuality and the family institution.
\end{abstract}

Key words: Spain, LPRS (Social Danger and Social Rehabilitation Act), marginal groups, transition, sexual liberation, revolutionary parties.

Recibido: 05/04/2017. Aceptado: 24/05/2017.

* Doctor en Filosofía. Profesor de EE. SS. en el I.E.S. "Martínez Montañés" (Sevilla). Líneas de investigación: Filosofía Política; Historia y sociología del género y la sexualidad; Sociología de la desviación. Publicaciones más recientes: Galván, V.: «Sobre la libertad y la verdad en Michel Foucault», Revista de Humanidades UNED (Sevilla), n 32, Septiembre-Diciembre, 2017, pp. 11-23; Galván, V.: «El desencanto del mundo: el político, el científico y el moralista», Andalucía Educativa. Revista Digital de la Consejería de Educación, (Sevilla), nº 89 Mayo, 2017,pp.8-21. E-mail: guiomar40@hotmail.com. Quiero mostrar mi especial agradecimiento a los/as libreros/as de la Plaza Tirso de Molina de Madrid, por su resistencia. 


\section{Introducción: El orden franquista, noche oscura del alma}

Este trabajo indaga sobre la estructura jerárquica entre los sexos desde su dimensión política y cultural, producto de las desigualdades históricas desplegadas en la arena política española durante una etapa que posibilitó un punto de inflexión hacia la inclusión e igualdad de las diferencias como cauces de superación de la marginalidad. Giros subjetivos e identidades escindidas que traemos a colación a través de la confluencia de los movimientos de liberación sexual del estado español durante el período referido.

Desde la perspectiva teórica abordada la identidad es una categoría histórico-cultural transferida en valores y actitudes, diversificada por el género, la etnia, la clase y/o la cultura profesional, por lo que las transacciones socio-existenciales recrean identidades ${ }^{1}$. Por su parte, el imperio civilizatorio del siglo XX acabó imponiendo una determinada economía afectiva heterosexual, configurada por un pensamiento binario complementario y definida por unas relaciones y usos amorosos bajo el ideal romántico donde el matrimonio y la institución familiar permaneciera como la más alta culminación y logro emocional. Como consecuencia, las identidades sexuales se presentaban bajo un destino biológico y una predeterminación antropológica, dependiendo de su relación con la normalidad definida, en primera instancia, por los expertos. Sin embargo, a finales de los años sesenta del siglo pasado se produjo un giro copernicano respecto a las teorías de la sexualidad: del esencialismo que mostraba una sexualidad instintiva e impulsiva -representada por el modelo heterosexual con dominio genitalfalocéntrico- se pasó a conceptualizar la sexualidad como un complejo proceso en construcción en relación a su socialización ${ }^{2}$.

En esta línea metodológica primamos al sujeto sobre el objeto, a las estrategias y tácticas sobre las estructuras donde constatamos valores y normas que circunscriben diferencialmente a los sexos, en derechos y obligaciones, a partir de la resistencia de los movimientos de liberación sexual durante la transición política. Sin duda, estas experiencias generaron dinámicas, discursos y prácticas desafiantes, sin constreñirse a binomios excluyentes, y así realizar una revisión conjunta del sistema sexo-género ${ }^{3}$.

El orden moral impuesto por la dictadura franquista se inscribía en una de las tradiciones más sólidas y arraigadas del nacional-catolicismo, como la aversión al goce sexual, la intangibilidad de la familia y la función biológica de la mujer limitada a las estructuras

1 Anna Jónasdóttir sostiene, en contraposición a otros tipos de valores y bienes como los socio-económicos, que los valores y bienes sexuales no pueden comprarse ni extraerse a la fuerza -otra cuestión es la prostitución y la trata de seres humanos- sino que han de ponerse a disposición sin condiciones en una relación sexualmente diferenciada con los demás. Para la autora las relaciones sexuales de poder son el resultado de un "amor entregado libremente" que recrea identidad, bajo la tutela de una larga trayectoria de educación sexista; de ahí que dichas relaciones no se reduzcan a una mera cuestión de dependencia económica. Véase A. Jónasdóttir: El poder del amor: ¿le importa el sexo a la democracia?, Madrid, Cátedra, 2000, p. 274.

2 A. Puleo: Dialéctica de la sexualidad. Género y sexo en la filosofía contemporánea, Madrid, Cátedra, 1992, p. 5.

3 J. Scott: «Gender: A useful category of historical analysis», American Historical Review, vol. 91, n5, 1986, pp. 1053-1075; G. Rubin: «The Traffic in Women: Notes on the 'political economy' of the sex», en: R. Reiter (ed.): Toward and anthropology of women, Monthy Review Press, Nueva York-Londres, 1975. De la misma autora, «Reflexionando sobre sexo: notas para una teoría radical de la sexualidad», en: C. S. Vance (comp.): Placer y Peligro, Madrid, Revolución, 1989, pp. 113-190. 
patriarcales $^{4}$. Esta ideología reaccionaria y represiva atentaba contra el desorden de los instintos, la concupiscencia y el libertinaje. Como consecuencia, en las familias se fomentaba el rechazo y el encierro de homosexuales, lesbianas y transexuales, considerados como enemigos de los principios católicos y puritanos. Durante décadas, desde las altas esferas del poder, se esforzaron en inculcar las nociones de norma y desviación, mandamiento y pecado, con el deliberado propósito de transformar a la mayoría en un rebaño de seres culpables y enfermos, encerrados en la problemática sin salida de una lucha permanente y estéril contra su propio cuerpo.

Un policía conocido como Mauricio Kart escribió Sodomitas en 1956, alcanzando su décimo segunda edición en 1973. En el ensayo, sin ningún rigor científico, podemos leer pasajes como este: la manada de fieras sodomitas, por millares, se lanza a través de la espesura de las calles ciudadanas en busca de su presa juvenil. Disfrazada de persona, la fiera sodomítica ojea entre el matorral ambulante de las aceras su pieza preferida, el cándido muchacho, más grato a su ávida pupila cuanto más inocencia lleva retrasada en su fisonomía (...) Vuestro hijo puede volver a casa corrompido, guardando su bochornoso secreto, que nada delatará; la monstruosa relación continuará y, dada su edad, su instinto sexual se torcerá y será para siempre un invertido ${ }^{5}$. Todavía en 1967 se dictaban Sentencias del Tribunal Supremo donde el Juez utilizaba los siguientes calificativos contra los actos homosexuales: contranatura, torpes, impropios de personas cultas, libidinosos, obscenos, impúdicos, repugnantes, inmorales, viciosos, de extravío sexual, lúbricos, ofensivos contra la moral media de los pueblos cultos, lascivos, que ponen al descubierto los bajos fondos sociales 6 .

A su vez, en los años 70 constatamos una sociedad en proceso de cambio con el fin de la autarquía, el relevo generacional, un mayor contacto con el exterior a través de la emigración y el turismo, más presencia de las mujeres en los distintos niveles educativos y en el ámbito laboral, etc. Con estos antecedentes y ante la oleada de expresiones homosexuales, la proliferación de la prostitución y pornografía, el consumo de drogas y alcohol, el vandalismo juvenil etc., se iniciaron los trabajos parlamentarios de reforma que condujeron a la aprobación de la Ley de Peligrosidad y Rehabilitación Social (LPRS) en 19707. Antonio Sabater y Tomás redactó el Anteproyecto de la LPRS, cuyo texto revela criterios subjetivos, discriminatorios y denigratorios hacia diferentes grupos marginados, en especial a los homosexuales y gitanos. Valga como anécdota el comentario del célebre Juez Especial de Peligrosidad Social de Barcelona: La actitud de los Beatles, con sus canciones en pro de la droga, causó efectos perniciosos en las mentes inmaduras e impresionables de los jóvenes ${ }^{8}$.

4 A través de los preceptos patriarcales, falocráticos y misóginos, consolidados en el largo invierno franquista por la connivencia del Estado y la Iglesia, las mujeres fueron meros sujetos destinados a la procreación, constituyendo un pecado capital la práctica sexual sin tal objetivo, y erigiendo la unidad familiar en una comunidad natural anterior a la sociedad civil.

5 M. Carlavilla: Sodomitas, Madrid, Editorial NOS, 1973, pp. 11-12.

6 M. Mapelli y M. Grosso: «La cuestión homosexual. El problema legal», El Viejo Topo, n 23, Agosto, 1978, pp. 18-20.

7 A. Fernández: «Justicia y sociedad bajo el franquismo: de la Ley de Vagos y Maleantes a la Ley de Peligrosidad y Rehabilitación Social, Franquismo, delincuencia y cambio social», en: J. Tusell (y otros): El régimen de Franco (1936-1975). Política y relaciones exteriores, Madrid, UNED, Tomo II, 1993, pp. 87-96.

8 A. Sabater: Peligrosidad social y delincuencia, Barcelona, Nauta, 1972, p. 128. 


\section{De vagos y maleantes a peligrosos sociales: la convergencia de los movimientos de liberación sexual}

La Ley 16/1970, de 4 de agosto, sobre Peligrosidad y Rehabilitación Social (LPRS) mantenía los principios de la Ley de Vagos y Maleantes (LVM), vigente durante la II República desde 1933. Esta última fue promulgada con el objetivo de defender a la sociedad frente a los sujetos temibles aún antes de que delincan. La LVM se reformó en 1954 para incluir en el marco de su aplicación a homosexuales, rufianes y proxenetas ${ }^{9}$. La LPRS definía diecisiete supuestos de estado peligroso, en particular según el artículo $2^{\circ}$ y $3^{\circ}$ : serán declarados en estado peligroso y se les aplicarán las correspondientes medidas de seguridad, quienes: (...) se aprecie en ellos una peligrosidad social. Son supuestos de estado peligroso los siguientes: (...) los que realicen actos de homosexualidad ${ }^{10}$. Las medidas de seguridad se concretaron en el internamiento en un establecimiento de reeducación que dotados del personal idóneo necesario garantizarán la reforma y rehabilitación social del peligroso y en la prohibición de residir en el lugar o territorio que se designe (artículo $6^{\circ}$ ). Según esta ley, la duración de la pena para homosexuales y prostitutas oscilaba entre seis meses y cinco años; y sobre los citados establecimientos de reeducación se crearon dos: un Centro para homosexuales pasivos en Huelva, y otro para homosexuales activos en Badajoz ${ }^{11}$. En el caso de una mujer lesbiana la ley no preveía su destino, si bien es cierto que las denunciadas por su homosexualidad fueron muy escasas.

A partir de la LPRS, durante el Gobierno de Carrero Blanco, se inició el movimiento social de liberación de gays y lesbianas. Desde Cataluña se extendió por todo el Estado: Valencia, Mallorca, Madrid, Málaga, Zaragoza, Santiago de Compostela, Bilbao, etc. La Agrupación Homosexual para la Igualdad Sexual editó en enero de 1972 el Boletín clandestino mensual AGHOIS ${ }^{12}$ (contracción del grupo) en el que se publicaron textos sobre la problemática homosexual desde perspectivas tan dispares como la jurídico-legal, religiosomoral, médico-científico, socio-político o histórico-biográfico ${ }^{13}$. A finales de 1975 un tribunal de Barcelona condenaba a un hombre por declarar su homosexualidad, con la pena de expulsión del territorio catalán y con el internamiento en el Centro Penitenciario para

9 A. Arnate: Redada de violetas. La represión de los homosexuales durante el franquismo, Madrid, La esfera de los libros, 2003; F. Olmeda: El látigo y la pluma: homosexuales en la España de Franco, Madrid, Oberon, 2004; A. Mira: De Sodoma a Chueca, Madrid, Egales, 2004; M. A. Soriano: La marginación homosexual en la España de la Transición, Madrid, Egales, 2005.

10 Citado por R. Llamas y F. Vila: «Spain: pasión for life. Una historia del movimiento de lesbianas y gays en el estado español», en: X. Buxán: Conciencia de un singular deseo, Barcelona, Laertes, 1997, pp. 189-224, p. 193.

11 C. Lorenzo: Cárceles en llamas. El movimiento de presos sociales en la Transición, Barcelona, Virus Editorial, 2013.

12 En Diciembre de 1972, AGHOIS contaba con un centenar de suscriptores. Para evitar riesgos el Boletín se imprimía en París por el grupo Arcadie, apareciendo desde el número 5 como Suplemento de Arcadie para los amigos de España. El Boletín se publicó en Francia hasta 1974, aunque ya en el 73 el Ministro de Asuntos Exteriores, López Rodó, intervino para que no se publicase en París.

13 A. Fluviá: «Los movimientos de liberación homosexual en el Estado español», en: M. S. Weinberg y C. J. Willians (eds.): Homosexuales masculinos. Sus problemas y adaptación, Barcelona, Fontanella, 1977, pp. 485-501. También véase, A. Fluviá: Aspectos jurídico-legales de la homosexualidad, Barcelona, Instituto Lambda, 1979. 
psicópatas de Huesca. Como protesta, un grupo de psiquiatras firmaron el "Documento de los 24" con la pretensión de que las autoridades y la sociedad machista española cambiase sus prejuicios sobre la homofobia ${ }^{14}$.

Cabe subrayar que los partidos políticos y los movimientos de liberación de la mujer -legales o no- podían realizar abiertamente sus campañas; al tiempo que los movimientos de homosexuales se mantenían en la clandestinidad ${ }^{15}$. En 1965 se celebraba en Barcelona la $1^{\text {a }}$ Asamblea General en la que se constituía el Movimiento Democrático de Mujeres $(\mathrm{MDM})$ que agrupaba a mujeres comunistas, socialistas, cristianas y sin filiación política ${ }^{16}$. Luchaban no sólo en pro de la democracia sino también por sus derechos civiles, laborales y sociales. Entre sus actividades, aunque fueron limitadas por la realidad social en que vivían, cabe destacar la confección de octavillas y panfletos; charlas en colegios e Iglesias; escritos dirigidos a autoridades civiles; mítines relámpago en los mercados; e incluso editaron el boletín mensual La mujer y la lucha.

La Asociación de Mujeres Juristas se creó en 1971, entre sus intereses promovieron la reforma del Derecho de Familia. Como consecuencia, a través de la ley de 2 de Mayo de 1975 desaparecía la licencia marital y la obligación de obediencia al marido. Las mujeres con inquietudes feministas se valieron de la proclamación de la ONU como Año Internacional de la Mujer en 1975 para denunciar las discriminaciones que sufrían. Desde 1974 mantuvieron contactos con la Asociación Española de Mujeres Separadas (AEMS), centrada en materia de separaciones y anulaciones matrimoniales en tanto que el divorcio aún no estaba legalizado en España; con la Asociación Española de Mujeres Universitarias (AEMU) y con diversas asociaciones de amas de casa y grupos cristianos para la elaboración de un programa común feminista y democrático que presentaron a la prensa en febrero de 1975. Estas circunstancias propiciaron las condiciones necesarias para la organización de las Primeras Jornadas Nacionales por la Liberación de la Mujer, celebradas en Madrid del 6 al 9 de Diciembre, a los pocos días de la muerte de Franco. Dicho evento, al que asistieron unas quinientas mujeres, se considera el primer encuentro feminista de carácter nacional celebrado en España ${ }^{17}$. Sus reivindicaciones giraban en torno a la educación, el trabajo, la familia y la sociedad en general; así como en la necesidad de crear un amplio movimiento feminista que ya albergó las dos posturas que polarizaban en esos años el debate feminista: el feminismo radical que defendía la militancia única en el feminismo, representado por el Seminario Colectivo Feminista de Madrid que más tarde se desdobló en el Colectivo Feminista; y el feminismo de lucha de clases, con objetivos políticos más generales que amparaba la participación tanto en organizaciones políticas y sindicales como feministas.

14 M. A. Soriano: Homosexualidad y represión. Iniciación al estudio de la homofilia, Madrid, Zero, 1978. El grupo de liberación homosexual Dignitat publicó el "Documento de los 24" en su Boletín del 11 de Enero de 1976. También véase, M. A. Soriano: «El comportamiento homosexual», Ozono, Diciembre, 1978, n 39, pp. 46-58.

15 M. A. Larumbe: «El feminismo en la transición democrática», Revista de cultura aragonesa, $\mathrm{n}^{\circ}$ 111-112, 2005, pp. 22-25.

16 A. Moreno: «La réplica de las mujeres al franquismo», en: P. Folguera (ed.): El feminismo en España. Dos siglos de Historia, Madrid, Fundación Pablo Iglesias, 2007, pp. 123-156. Sobre la lucha feminista española bajo el franquismo, véase del mismo autor: Mujeres en lucha. El movimiento feminista en España, Madrid, Anagrama, 1977.

17 P. Folguera: «De la transición política a la paridad», en: P. Folguera (ed.): El feminismo en España. Dos siglos de Historia, opus cit. (2007), pp. 157-200. 
Con posterioridad las mujeres reivindicaron una tercera vía: la de aquellas que aún aceptando la doble militancia insistían en la necesidad del movimiento feminista para definir sus prioridades y elegir sus estrategias. Esta postura la sostuvo el Frente de Liberación de la Mujer que se constituyó en Madrid en enero de 1976. También se organizaron en Barcelona las I Jornades Catalanes de la Dona -mayo de 1976- que junto con las anteriores jornadas marcaron no sólo el período de expansión del movimiento feminista en nuestro país, sino también una auténtica eclosión de organizaciones de mujeres, aunque muchas de éstas de carácter efímero. Asimismo cabe mencionar el tercer gran encuentro del feminismo español durante la Transición, las II Jornadas Estatales de la Mujer celebradas en Granada en mayo de 1979. Al anterior debate sobre la militancia única o doble, se le añadió otro más novedoso: el del feminismo de la igualdad y el feminismo de la diferencia ${ }^{18}$.

A pesar de los distintos enfoques grupales, desde 1978 existía cierta coordinación para acciones conjuntas mediante la Plataforma de Organizaciones y Grupos de Mujeres. Ésta impulsó campañas, como las acaecidas en 1976 y 1977, por la amnistía para los delitos de aborto, anticoncepción, adulterio y prostitución que mantenían en las cárceles a cientos de mujeres. Con sus reivindicaciones consiguieron despenalizar en 1978 tanto el adulterio y amancebamiento como el uso, propaganda y difusión de los anticonceptivos; mientras que la disputa por el divorcio y el derecho al aborto seguiría abierta durante años. El papel de las mujeres, como consecuencia de los diferentes encuentros del feminismo español, fue adquiriendo más relevancia en los partidos políticos y organizaciones sindicales. A su vez la recuperación del 8 de marzo como Día Internacional de la Mujer Trabajadora sirvió de punto de confluencia para las acciones de solidaridad del movimiento feminista con las trabajadoras y sus conflictos laborales. Con el triunfo del PSOE en las elecciones generales de 1982 finalizaba la transición y la desmovilización política, que también afectó al movimiento feminista. Por su parte, en 1983 se creó el Instituto de la Mujer que comportaba un feminismo institucionalizado, extendiéndose a las Comunidades Autónomas con la creación de organismos similares.

\section{El Manifiest del Front d'Alliberament Gay de Catalunya}

El objetivo fundamental de la Agrupación Homosexual para la Igualdad Sexual (AGHOIS), organización identificada posteriormente como Movimiento Español de Liberación Homosexual (MELH), consistió en concienciar a los homosexuales en la reivindicación de sus derechos, romper con su aislamiento y lograr el reconocimiento y aceptación de la sociedad. Tras la muerte del dictador sus integrantes reforzaron el perfil ideológico y se denominaron Front d'Alliberament Gay de Catalunya (FAGC) ${ }^{19}$. En el I Congreso Internacional de Marginación Social de 1976, celebrado en Burjassot (Valencia), el FAGC mantuvo contactos con jóvenes estudiantes y trabajadores, constituyéndose el Front d'Alliberament Homosexual del País Valencià (FAHPV), y en Mallorca el Front d'Alliberament Gay de les

18 A. Moreno: «La réplica de las mujeres al franquismo», en: P. Folguera (ed.): El feminismo en España. Dos siglos de Historia, opus cit. (2007), pp. 123-156.

19 A. Fluviá: «El movimiento homosexual en el estado español», en: J. E. Enríquez, y otros (eds.): El homosexual ante la sociedad enferma, Barcelona, Tusquets, 1978, pp. 149-167; E. Haro: «La homosexualidad, una herejía de nuestro tiempo», Triunfo, ${ }^{\circ}$ 82, 1978, 25 de Noviembre, p. 59. 
Illes (FAGI). A partir de diferentes asambleas constituyentes aprobaron un Manifiesto que notificaron a los partidos políticos - desde el centro izquierda a la izquierda más radical- y a la prensa, con la intención de que se posicionaran sobre la homosexualidad.

El Manifiesto de Marzo de 1977 del Front d'Alliberament Gay de Catalunya es el primer análisis político de la cuestión homosexual. Este texto se utilizó de base para una definitiva elaboración de la teoría de la liberación sexual, sirviendo de plataforma orientativa para los movimientos gays en el resto del Estado español. Las reivindicaciones fundamentales del FAGC fueron la Derogación de la LPRS $^{20}$ y la Amnistía para todos los encarcelados y recluidos por causa de su conducta homosexual. La ideología del Manifiesto partía de un análisis marxista de la sexualidad: creemos que la lucha por nuestras libertades está inmersa dentro de una lucha por la liberación sexual del individuo y ésta está dentro de la lucha por la liberación total del individuo humano, e inmersa en la lucha de clases. Nosotros no somos reformistas, somos radicales y revolucionarios. No nos contentamos con que cambien las leyes. Hay una serie de estructuras que oprimen a una serie de gente: la familia, la escuela, que tal como están establecidas por la clase dominante, es necesario cambiarlas ${ }^{21}$. En las filas del FAGC había afiliados y simpatizantes de partidos políticos como Acción Catalana, Federación de Partidos Socialistas (FPS), Partido Socialista Popular (PSP), Partit Socialista Unificat de Catalunya (PSUC), Partido Comunista de Unificación (PCU), Movimiento Comunista (MC), Liga Comunista Revolucionaria (LCR), Acción Comunista (AC), Confederación Nacional de Trabajadores (CNT), y la Organización de Izquierda Comunista de España $(\mathrm{OICE})^{22}$.

Los mejores aliados del FAGC fueron los movimientos de liberación de la mujer, en concreto el colectivo de Mujeres Libres, al dilucidar que la opresión sobre la mujer y los homosexuales derivaba de la misma ideología sexista y machista. Esta unidad de acción serviría para aunar esfuerzos y lograr sus pretensiones: el FAGC, invita a todos los movimientos de mujeres y entre ellas a Mujeres Libres a colaborar conjuntamente en nuestra lucha para acabar con las segregaciones de todo tipo y para conseguir la total liberación sexual $^{23}$. Mujeres Libres resurgió con el mismo nombre en 1975, puesto que funcionó como grupo homónimo entre 1936 y $1939^{24}$. Entre las demandas de esta organización libertaria y

20 «Aspectos reivindicativos del FAGC y del FHAR», El Viejo Topo, n 8, Mayo, 1977, pp. 36-37.

21 P. Viladegut y D. Solís: «Todos somos bisexuales» (Entrevista con el secretario general del FAGC), El Viejo Topo, $\mathrm{n}^{\circ}$ 8, Mayo, 1977, pp. 34-35.

22 Mesa redonda: «Homosexuales, una lucha marginal», Teoría y práctica. La lucha de clase analizada por sus protagonistas, $\mathrm{n}^{\circ} 12$, Octubre, 1977, pp. 78-87. En el coloquio intervinieron miembros del FAGC, Dignitat y una representación de homosexuales independientes. Véase, Front D’Alliberament Gai de Catalunya: «Aspectos diversos de la tortura infligida a los homosexuales», Clínica y análisis grupal, Noviembre-Diciembre, 1977, nº 7, pp. 66-82.

23 Helios: Documento «Hacia la total liberación sexual», en: VV. AA.: Mujeres Libres. Aproximación a Mujeres Libres, Barcelona, Memorial Democràtic, 1977, pp. 231-233, p. 233. Véase, M. Sanfeliu: «Educando y viviendo en la libertad sexual. Mujeres libres y Lucía Sánchez Saornil», en: R. Osborne (ed.): Mujeres bajo sospecha. Memoria y sexualidad, 1930-1980, Madrid, Fundamentos, 2012, pp. 331-345.

24 M. Nash: Mujeres libres: España 1936-1939, Barcelona, Tusquets, 1976. Sobre Mujeres Libres véase, L. Quiñonero: «Sueños y pesadillas de las Mujeres Libres», Viento Sur: Por una izquierda alternativa, $\mathrm{n}^{\circ}$ 93, 2007, pp. 107-116; J. Ma Montero: Anarcofeminismo en España. La Revista Mujeres Libres antes de la guerra civil, Madrid, Fundación Anselmo Lorenzo, 2003; S. Berenguer: Mujeres Libres. Luchadoras libertarias, Madrid, Fundación Anselmo Lorenzo, 1999; M. Ackelsberg: Mujeres libres. El anarquismo y la lucha por la emancipación de las mujeres, Barcelona, Virus, 1999. 
autónoma subrayaban la división sexual tanto en la vida cotidiana como en la acción política: aún estando en contra del capital y del trabajo asalariado hicieron suya la proclama "a igual trabajo, igual salario". Por supuesto, exigían la derogación de la LPRS y rechazaron la división entre presos comunes y políticos; así como el derecho de todas y todos a disponer de sus cuerpos preservando el amor libre. Es decir, se opusieron al matrimonio y a la familia por ser los pilares básicos de reproducción de la sociedad autoritaria.

Tras el Manifiesto surgieron varios grupos de liberación homosexual. En Madrid destacamos: el Frente Homosexual de Acción Revolucionaria (FHAR), el Movimiento Democrático de Homosexuales (MHD) y la Agrupación Mercurio para la Liberación Homosexual25; en Málaga, la Unión Democrática de Homosexuales de Málaga (UDHM); y en Bilbao, Euskal Herriko Gay Askaten Mugimendua (EHGAM). La mayoría de estas organizaciones se caracterizaron por sus pretensiones radicales y revolucionarias de tipo social y político. El FHAR no estuvo adscrito a ningún partido político, pero fueron conscientes de la convergencia imprescindible entre los movimientos de liberación de la mujer y los de liberación homosexual, por lo que colaboraron con el movimiento feminista. Para la Agrupación Mercurio ${ }^{26}$ -democrática, asamblearia y abierta a todas las ideologías- era necesario subvertir el orden socio-económico para conseguir la liberación sexual por otro que permitiese la superación de la lucha de clases. Por su parte, el MDH pretendía encontrar alternativas democráticas en vías del socialismo, en tanto que la sociedad de clases y las instituciones fueron históricamente la base de la represión, y de la incesante condena y persecución de la homosexualidad.

En el mismo mes de Marzo de 1977 coincidieron, en la Universidad Complutense de Madrid, la Primera Semana de Solidaridad con los Presos Comunes ${ }^{27}$ y la Semana contra la Ley de Peligrosidad y Rehabilitación Social, organizadas respectivamente por la Facultad de Derecho y por la Coordinadora de Grupos Marginados a la que pertenecían el FHAR y la Agrupación Mercurio. Se abrieron las jornadas con la presentación "El pregón de la fiesta" del coordinador J. López Linage, para después tomar la palabra los colectivos de mujeres, homosexuales, presos comunes, psiquiatrizados, minusválidos y algunas organizaciones políticas que reclamaban el derecho a ser diferentes ${ }^{28}$. Estos informes constituyen un texto imprescindible para la comprensión de los movimientos sociales durante la transición que vio la luz con el título de Grupos marginados y Peligrosidad Social ${ }^{29}$. El primer comunicado -Abril de 1977- de la Coordinadora de Grupos Marginados lo firmaron las siguientes organizaciones: Acción Comunista (AC), Comités de Apoyo a COPEL, Confederación Nacional del Trabajo (CNT), Frente Homosexual de Acción Revolucionaria (FHAR), Frente de Liberación de la Mujer (FLM), Juventudes Comunistas Revolucionarias (JCR), Juventudes Socialistas (JJSS), Liga Comunista Revolucionaria (LCR), Mujeres Libres, Organización

25 Agrupación de homosexuales Mercurio: «Declaración de principios y objetivos», Plataforma. Revista universitaria de información nacional, $\mathrm{n}^{\circ}$ 27, 3 de Marzo, 1977.

26 En Julio de 1977 la Agrupación Mercurio se fusionó con algunos miembros del FHAR y el MDH, constituyendo el Frente de Liberación Homosexual de Castilla (FHHOC).

27 Jornadas celebradas del 21 al 25 de Marzo de 1977 en la Facultad de Derecho de la Universidad Complutense de Madrid, organizadas por la Asociación Cultura y Derecho que presidía F. J. Álvarez García.

28 R. M. Pereda: «Los grupos contra la ley de Peligrosidad Social», El País, 10 de Noviembre, 1977.

29 J. López: «El pregón de la fiesta» en, J. López (Coord.): Grupos marginados y Peligrosidad Social, Madrid, Campo Abierto Ediciones, 1977, pp. 7-13. También véase, F. Torres (coord.): Los marginados en España, Madrid, Fundamentos, 1978. 
de Izquierda Comunista (OIC) y por el Seminario Colectivo Feminista. Posteriormente se sumaron a la Coordinadora, el Colectivo de Psiquiatrizados en Lucha, Minusválidos Unidos, el Colectivo Feminista y los Grupos de Educación Especial ${ }^{30}$. La semana culminó con una mesa redonda en la Facultad de Derecho en la que intervinieron Agustín García Calvo, Fernando Savater y Javier López Linage, a la que finalmente no asistieron los filósofos invitados Félix Guattari y Michel Foucault ${ }^{31}$.

Los grupos de liberación homosexual -Agrupación Mercurio, FAGC, FHAR, MDM, UDHM, EHGAM, FAGI, FAHPV, Movimiento Homosexual Aragonés (MHA) y Movimiento de Liberación Homosexual de Granada (MLH)- hicieron público un comunicado en Mayo de 1977, en el que exigían la derogación de la LPRS y la disolución de los tribunales que aplicaban dicha ley. Asimismo mandaron un informe avalado con seis mil firmas a Landelino Lavilla ${ }^{32}$ en el que recordaban al Ministro de Justicia la adhesión de España a la Declaración Universal de los Derechos Humanos ${ }^{33}$. La mayoría de los colectivos citados decidieron unirse en sus acciones para constituirse como una única formación en la Coordinadora de Frentes de Liberación Homosexual del Estado Español (COFLHEE). Independientemente de los grupos mencionados, con un perfil ideológico y reivindicativo, también existieron otros colectivos de corte humanístico y cristiano con un carácter reformista e integracionista. Es el caso del sacerdote Antonio J. de Mora, director desde 1968 de la Fraternidad Cristiana de la Amistad $^{34}$, organización valenciana que atendía a los marginados sociales, aunque dedicada preferentemente a la orientación de homosexuales y lesbianas. Y en Barcelona, el ex-jesuita Salvador Guash i Figueras fundó en 1976 el grupo Dignitat, semejante al movimiento norteamericano Dignity en el que sólo tenían cabida los católicos, con la particularidad para el caso español de caracterizarse por ser un grupo pluralista que admitía a agnósticos y ateos ${ }^{35}$.

Conviene subrayar que la diferencia conceptual entre homosexualidad y transexualidad era imprecisa, lo que propició que existieran divergencias entre dichos colectivos. Como consecuencia constituyeron en 1977 la Coordinadora de Collectius per l'Alliberament Gay (CCAG), dentro de la cual se organizó el Colectivo Delincuencia y Marginación, en el que

30 «Coordinadora de Grupos marginados de Madrid por la abolición de la Ley de Peligrosidad y Rehabilitación social», en: J. López (coord.): Grupos marginados y Peligrosidad Social, opus cit. (1977), pp. 24-27.

31 Sobre la influencia de Michel Foucault en los movimientos de liberación sexual en España, véase V. Galván: «Ni masculino ni femenino sino todo lo contrario» en: De vagos y maleantes. Michel Foucault en España, Barcelona, Virus, 2010, pp. 136-165.

32 La rueda de prensa se celebró el 21 de Mayo de 1977 en el Club de Amigos de la UNESCO de Madrid. El diario El País publicó una nota de prensa el 22 de Mayo sobre la carta dirigida al ministro de Justicia: seis mil firmas promovidas por los grupos homosexuales. Se pide la derogación de la Ley de Peligrosidad Social. La carta está firmada por el Presidente de la Asociación de Derechos Humanos, Joaquín Ruiz-Giménez, Rafael Alberti, Pablo Castellano, Antonio Gala, Juan Antonio Bardem, Eloy de la Iglesia, Pedro Olea, etc.

33 M. A. Soriano: Homosexualidad y represión. Iniciación al estudio de la homofilia, opus cit. (1978), p. 116.

34 Este grupo organizó el Primer Congreso Internacional de Marginación Social, celebrado en Burjassot (Valencia) los días 1 y 2 de Mayo de 1976. En el encuentro participaron, entre otros, el psiquiatra Manuel Gómez-Beneyto, el sociólogo José Vicente Marqués y el teólogo Enrique Miret.

35 La Primera Asamblea de Dignitat se celebró en Montserrat los días 16 y 17 de Octubre de 1976. En Dignitat existía un grupo de apoyo al homosexual deprimido para luchar contra sus propios prejuicios. Como consecuencia de esta división se fundó el movimiento "Fénix de homosexuales" que trabajaban para la integración social de las personas marginadas. 
se integraron un grupo de travestis y transexuales denominado La Pluma. Mientras tanto, se celebraba en Barcelona el Día Mundial del Orgullo Gay el 26 de Junio de 1977 en las Ramblas. En el comunicado hecho público se explicaba el doble motivo de la convocatoria: la inmediata derogación de la discriminatoria LPRS y festejar por primera vez en nuestro país el Día Mundial del Orgullo Gay, fecha en la que se conmemora el inicio de las movilizaciones homosexuales en el mundo ${ }^{36}$. Sin embargo, los sucesos fueron lamentables no sólo porque la manifestación fue brutalmente reprimida por la policía antidisturbios con varios agredidos y detenidos ${ }^{37}$, sino sobre todo porque los travestis y transexuales fueron despreciados por parte de algunos grupos cercanos al colectivo convocante, el Front d'Alliberament Gay de Catalunya. El motivo fue controvertido, ya que algunos de éstos rechazaron que el imaginario del travestismo copara en primera línea la acción pública de la manifestación, lo que acabó por fracturar a los grupos disidentes. De este modo, los travestis que habían apoyado al FAGC se disgregaron para fundar en 1979 -con mucha menor visibilidad en los documentos y las fuentes consultadas- el Collectiu de Travestis i Transexuals de Barcelona (CTT). El CTT participó en movilizaciones sociales, disturbios y manifestaciones contra la represión que venían sufriendo desde la década de los setenta y la práctica marginalidad que aún persiste en la actualidad ${ }^{38}$.

Como consecuencia de la aprobación de la Constitución Española -en Diciembre de 1978- quedaba derogada la LPRS por ser incompatible con la democracia, básicamente en lo referente al concepto de peligrosidad social y al de capacidad de rehabilitación. Estas contrariedades fueron subsanadas por vía de urgencia, en Enero de 1979, con una reforma legal en la

36 El antecedente inmediato se halla en las revueltas acaecidas durante en 1969 en el barrio neoyorkino de Greenwich Village y el pub "Stonewall Inn", por el hostigamiento a transexuales, gays y lesbianas y su disidencia en el movimiento de liberación. Un activismo en el que destacaron líderes marginales como las transexuales Marsha P. Johnson y Silvia Rivera. En los años sesenta, ambas mujeres encabezaron proyectos insurreccionales y antiasimilacionistas, creando una red de autogestión, apoyo mutuo y disidencia sexual. Entre sus acciones autogestionaron una casa financiada con el ejercicio de su propia prostitución para alojar a travestis -sin formación y en precariedad- con la finalidad de alejarlas del comercio sexual y de la drogodependencia. Presas de un "género variante" que hoy conformarían parte del legado del movimiento queer, antecedieron a la normatividad y la heterodesignación mediante continuas acciones revolucionarias y fracturas con otros grupos disidentes a quienes habían apoyado, especialmente a gays y lesbianas que más tarde las despreciaron. Sobre la autoorganización, revolución queer y transfeminista del grupo STAR (Street Transvestite Action Revolutionaries), véase S. Rivera y M. Johnson: STAR: Acción Travesti Callejera y Revolucionaria. Supervivencia, revuelta y lucha trans antagonista, Madrid, Ed. Imperdible, 2015.

37 El diario catalán Mundo Diario publicaba en sus columnas: En la pasada madrugada fue presentada una demanda en el Juzgado de Guardia por los presuntos malos tratos inferidos por la Policía a un detenido en la manifestación gay del pasado domingo en las Ramblas. La denuncia fue admitida a trámite por el juez, que, al parecer, habló con la denunciante y una testigo de la paliza inferida a Oriol Martí Casas, militante de OCEBR (Organización Comunista de España-Bandera Roja), médico y PNN de la Universidad Autónoma. Oriol Martí fue ingresado en la cárcel Modelo, y al parecer, se le ha abierto sumario por posible agresión a la fuerza armada por parte de la jurisdicción militar. Véase, Mundo Diario, 29 de Junio, 1977.

38 Para una revisión de los movimientos sociales "trans" en España, véase S. Rivera y M. Johnson: STAR: Acción Travesti Callejera y Revolucionaria. Supervivencia, revuelta y lucha trans antagonista, opus cit. (2015), pp. 127-136; J. B. Eres y C. Villagrasa (coord.): Homosexuals $i$ Transsexuals. Els altres represaliats $i$ discriminats del franquisme, des de la memòria històrica, Barcelona, Bellaterra, 2000; R. Platero: «Transexualidad y agenda política: una historia de (dis)continuidades y patologización», Política y sociedad, vol. 46, n 1 y 2, 2009, pp. 107-128; R. Platero: Trans*exualidades: Acompañamiento, factores de salud y recursos educativos, Barcelona, Bellaterra, 2014. 
que se eliminaron varios artículos de la ley, entre éstos el de los actos de homosexualidad. No sólo se trataba de cambiar y derogar leyes sino también de que los gays y lesbianas tomaran la palabra para cambiar estructuras y derribar prejuicios. En el siguiente comunicado, considerado como uno de los primeros manifiestos públicos del Col-lectiu de Lesbianes de Barcelona leemos: es preciso, pues, que nuestra voz se oiga para des-velar y re-velar los aspectos comunes de nuestra realidad como mujeres y reivindicar nuestra diferencia como lesbianas ${ }^{39}$. Las mujeres durante el franquismo tuvieron que tolerar la dominación ejercida como instrumento de placer del hombre, mientras que las mujeres lesbianas sufrieron la invisibilidad. A principios de 1977 constituyeron un Colectivo de Lesbianas independientes pero incluidas en el Front d'Alliberament Homosexual del País Valencià (FAHPV), con discrepancias sobre el enfoque de sus reivindicaciones e incluso por el modo de entender la sexualidad. El Colectivo de lesbianas perteneció, hasta Febrero de 1978, a los denominados Frentes Mixtos para incorporarse posteriormente al Movimiento Feminista (MF) como Colectivos de Lesbianas Feministas ${ }^{40}$.

\section{El último «pregón de la fiesta»: la cuestión homosexual y los partidos marxistas en la transición}

Hemos podido constatar que la mayoría de los movimientos de liberación sexual eran afines o simpatizantes a los partidos marxistas. Durante la dictadura y la transición se identificó al marxismo con la ideología enfrentada al régimen, sin poner en tela de juicio su postura generalizada respecto a la homosexualidad. La relación entre los sexos fue un tema secundario en la teoría marxista, centrada en el antagonismo de clases. Si bien, el ensayo de Engels, El origen de la familia, la propiedad privada y el Estado, se utilizó como base de explicaciones posteriores que desde el marxismo se dieron al conflicto de sexos. A partir de la teoría evolucionista del antropólogo Lewis Morgan, Engels identificaba el origen de la humanidad con un comunismo sexual donde no existía el tabú del incesto, para más tarde establecerse la monogamia a medida que el varón fue mostrando sus preferencias por una de sus mujeres ${ }^{41}$. En general, el marxismo y sus ideales de revolución antiburguesa condenaron la homosexualidad como un vicio habitual de las clases en el poder, e incluso Engels la rechazó por ser antinatural ${ }^{42}$. Con el triunfo de la Revolución rusa en 1917 se suprimieron las leyes antihomosexuales, y al menos legalmente el homosexual fue libre. Con la llegada de Stalin al poder, la homosexualidad se identificó como tara de la burguesía, así los países comunistas orientales y occidentales reprimieron la homosexualidad, e incluso omitían el término para evitar el debate en el partido. Por tanto, en los denominados países socialistas, la homosexualidad se condenaba públicamente como residuo decadente de la sociedad burguesa, al tiempo que no cuestionaron el modelo sexual burgués, ni tampoco la moral y la familia.

39 Citado por R. Llamas y F. Vila: «Spain: pasión for life. Una historia del movimiento de lesbianas y gays en el estado español», en: X. Buxán (ed): Conciencia de un singular deseo, opus cit. (1977), pp.189-224, p. 193.

40 Colectivo de Lesbianas, en: J. E. Enríquez (compilador): El homosexual ante la sociedad enferma, Barcelona, Tusquets, 1978, p. 181 y ss.

41 A. Puleo: «Dos escuelas de la sospecha: hombre y mujer en el materialismo histórico y el psicoanálisis», en: A. Puleo (y otros): La Filosofía, ¿es un arma cargada de futuro?, Madrid, Publicaciones del Ministerio de Educación y Ciencia, 1993, pp. 65-82.

42 F. Engels: El origen de la familia, la propiedad privada y el Estado, Madrid, Fundamentos, 1971. 
En España, el desmantelamiento paulatino de la dictadura y la transición aún comportaba formas visibles y escandalosas de represión corporal y sexual. Por un lado, asistíamos a las reivindicaciones feministas y a la toma de conciencia de los movimientos de liberación gay, al fenómeno del destape de revistas y publicaciones, a la denodada evolución de nuestras costumbres, etc. Pero en cambio, estos acontecimientos no sólo suscitaron el espanto y sorpresa -como pudiera esperarse- de los sectores más tradicionales y reaccionarios del régimen sino también de la propia izquierda. Las siguientes afirmaciones sobre la homosexualidad en boca de algunos de los líderes marxistas coincidían con la ideología de las clases dominantes, es decir, con los principios nostálgicos del nacional-catolicismo.

Los periodistas Fernando Ruiz y Joaquín Romero publicaron una entrevista realizada a nueve líderes de partidos marxistas en 1977. En el cuestionario se incluía la pregunta: ¿qué opinión te merece la homosexualidad? Y estas son algunas de las respuestas condenatorias de los dirigentes revolucionarios: en la sociedad actual, la homosexualidad no viene motivada por unos defectos físicos, sino ante todo por una degeneración de la vida. En este sentido, la homosexualidad debe ser condenada (Eladio García Castro, Partido del Trabajo de España, PTE) ${ }^{43}$. O la afirmación de Diego Fabregas, de la Organización de Izquierda Comunista (OIC): creo que en cierta medida se recurre a la homosexualidad por no ser capaces de afrontar otras responsabilidades y otras cuestiones. Por principio, no me opongo a que existan homosexuales, pero pienso que ni hay que estimularlos ni hacer una Liga para defenderlos ${ }^{44}$. Y esta otra de Manuel Guedan, de la Organización Revolucionaria de Trabajadores (ORT): la homosexualidad es una alteración de la sexualidad. No es una forma normal de entender las relaciones sexuales, no es natural y puede verse en un tipo de deformación educativa, psicológica o física ${ }^{45}$. Los prejuicios de los partidos marxistas insistían en el discurso ideológico sobre la homosexualidad y no en el individuo. Ésta era considerada como una consecuencia exclusiva de la sociedad burguesa capitalista, presuponiendo que en la futura sociedad socialista no podría existir la homosexualidad. También el arraigo histórico del machismo en nuestro país conlleva una lectura política: los partidos de izquierda y extrema izquierda, conscientes del tabú social que representaba la homosexualidad, hicieron todo lo posible por silenciar oficialmente su postura o abstenerse por temor a la pérdida de votos.

Los partidos políticos PTE, ORT y OIC fueron minoritarios en estos años de la transición, si bien éste no fue el caso del Partido Comunista de España (PCE). Esta es la opinión de Antonio Rato: creo que al delincuente se le debe aislar, por la misma razón que se aísla al portador de un virus o a un demente peligroso. Es decir, sin tratar de penetrar en el hondón de su conciencia, ni, micho menos, de evaluar hasta qué punto es responsable en concreto de su actual personalidad ${ }^{46}$. Y aún menos sospechoso de tales prejuicios el que fue Secretario General del Partido Socialista Popular (PSP), Enrique Tierno Galván quien aseveraba: lo mismo que no hay derechos específicos para otro tipo de alteraciones de lo que el consenso

43 F. Ruiz y J. Romero (Edición a cargo de): Los partidos marxistas. Sus dirigentes, sus programas, Barcelona, Anagrama, 1977, p. 164. El trabajo recoge nueve entrevistas con líderes de partidos marxistas y sus respectivos programas, más otros trece programas de partidos políticos cuya incidencia era relevante en algunas comunidades.

44 Ibidem, p. 93.

45 Ibidem, p. 108.

46 Ibidem, p. 98. 
común llama normal, aquí tampoco debe haberlas. En esto los socialistas somos muy claros: nosotros defendemos posiciones que se refieren a un consenso generalizado sobre lo que es bueno o malo. Puede que no nos pongamos cada día a discutir sobre lo que es bueno o malo, pero hay un consenso general que admitir. El viejo profesor utilizaba el mismo binomio de normalidad versus anormalidad que el sistema, no cuestionándose el significado y origen de lo bueno y lo malo sino que admitía el consenso general. Es decir, para él la normalidad era todo aquello que permitía conservar intacto el sistema, en cuya defensa y perpetuación actúan las instituciones, definidas desde y por el Poder.

El argumento de Tierno Galván no está exento de contradicción: si la mayoría o la opinión común juzgaba que la homosexualidad era un mal y ésta tenía que prohibirse, equivale a defender que cuando la mayoría de las sociedades admitían como un bien la esclavitud o el colonialismo, éstos debían de ser aceptados. Con estos antecedentes, las normas tradicionalmente acogidas por el consenso común son sagradas e inviolables: el hombre y la mujer deben ser educados en el orden intelectual y sexual para que sus instintos estén de acuerdo con una cierta normativa, no para que las normas sigan a los instintos. De esta manera, si una mujer o un hombre no pueden reducir sus instintos al canon de lo que se entiende por el sentido mayoritario que es normal, si no saben mantener unos principios ascéticos para que sirvan de modelo generador y de ayuda al proceso revolucionario, es que no tienen energía revolucionaria y, por tanto, eso es castigable, no tolerable ${ }^{47}$.

Es obvio que durante la transición la mayoría de los partidos revolucionarios eludieron enfrentarse a las normas y costumbres imperantes de la sociedad, en aspectos tan decisivos como la sexualidad, el erotismo, las relaciones interpersonales, las instituciones familiares, etc. El escritor Juan Goytisolo reflexionaba con lucidez sobre la paradoja de algunos líderes marxistas-leninistas, ya que denunciaban la explotación de los obreros en las fábricas, pero no en cambio la alienación que sufrían las mujeres en sus propias casas: se puede ser antiesclavista, pero burgués. Se puede ser republicano y colonialista. Se puede ser obrero, pero machista. Se puede ser defensor de los derechos de la mujer, los negros y los obreros, y perseguir a los homosexuales. Pero no se puede pretender el nombre de revolucionario sin extraer el común denominador de todas las opresiones, a fin de denunciarlas y combatirlas ${ }^{48}$.

\section{Referencias}

Ackelsberg, M.: Mujeres libres. El anarquismo y la lucha por la emancipación de las mujeres, Barcelona, Virus, 1999.

Agrupación de homosexuales Mercurio: «Declaración de principios y objetivos», Plataforma. Revista universitaria de información nacional, $\mathrm{n}^{\circ}$ 27, 3 de Marzo, 1977.

Arnate, A: Redada de violetas. La represión de los homosexuales durante el franquismo, Madrid, La esfera de los libros, 2003.

47 Las citas de Enrique Tierno Galván se encuentran en las páginas 131-147 del cuestionario citado.

48 J. Goytisolo: «Remedios de la concupiscencia según Fray Tierno», El Viejo Topo, n 16, Enero, 1978, Pág. 8-11, p. 11. 
Berenguer, S.: Mujeres Libres. Luchadoras libertarias, Madrid, Fundación Anselmo Lorenzo, 1999.

Carlavilla, M.: Sodomitas, Madrid, Editorial NOS, 1973.

Colectivo de Lesbianas, en: J. E. Enríquez (compilador): El homosexual ante la sociedad enferma, Barcelona, Tusquets, 1978.

Coordinadora de Grupos marginados de Madrid por la abolición de la Ley de Peligrosidad y Rehabilitación social, en: J. López (coord.): Grupos marginados y Peligrosidad Social, Madrid, Campo Abierto Ediciones, 1977, pp. 24-27.

Engels, F.: El origen de la familia, la propiedad privada y el Estado, Madrid, Fundamentos, 1971.

Eres, J. B. y Villagrasa, C. (coord.): Homosexuals $i$ Transsexuals. Els altres represaliats $i$ discriminats del franquisme, des de la memòria històrica, Barcelona, Bellaterra, 2000.

Fernández, A.: «Justicia y sociedad bajo el franquismo: de la Ley de Vagos y Maleantes a la Ley de Peligrosidad y Rehabilitación Social, Franquismo, delincuencia y cambio social», en: J. Tusell (y otros): El régimen de Franco (1936-1975). Política y relaciones exteriores, Madrid, UNED, Tomo II, 1993, pp. 87-96.

Fluviá, A.: «El movimiento homosexual en el estado español», en: J. E. Enríquez, y otros (eds.): El homosexual ante la sociedad enferma, Barcelona, Tusquets, 1978, pp. 149-167.

Fluviá, A.: «Los movimientos de liberación homosexual en el Estado español», en: Weinberg, M. S. y Willians, C. J. (eds.): Homosexuales masculinos. Sus problemas y adaptación, Barcelona, Fontanella, 1977, pp. 485-501.

Fluviá, A.: Aspectos jurídico-legales de la homosexualidad, Barcelona, Instituto Lambda, 1979.

Folguera, P.: «De la transición política a la paridad», en: P. Folguera (ed.): El feminismo en España. Dos siglos de Historia, Madrid, Fundación Pablo Iglesias, 2007, pp. 157-200.

Front D'Alliberament Gai de Catalunya: «Aspectos diversos de la tortura infligida a los homosexuales», Clínica y análisis grupal, Noviembre-Diciembre, 1977, nº 7, pp. 66-82.

Galván, V.: De vagos y maleantes. Michel Foucault en España, Barcelona, Virus, 2010.

Goytisolo, J.: «Remedios de la concupiscencia según Fray Tierno», El Viejo Topo, ${ }^{\circ}{ }^{16}$, Enero, 1978, Pág. 8-11.

Haro, E.:«La homosexualidad, una herejía de nuestro tiempo», Triunfo, $\mathrm{n}^{\circ}$ 82, 1978, 25 de Noviembre, p. 59.

Helios: Documento «Hacia la total liberación sexual», en: VV. AA.: Mujeres Libres. Aproximación a Mujeres Libres, Barcelona, Memorial Democràtic, 1977, pp. 231-233.

Jónasdóttir, A.: El poder del amor: ¿le importa el sexo a la democracia?, Madrid, Cátedra, 2000.

Llamas, R. y Vila, F.: «Spain: pasión for life. Una historia del movimiento de lesbianas y gays en el estado español», en: X. Buxán: Conciencia de un singular deseo, Barcelona, Laertes, 1997, pp.189-224.

Larumbe, M. A.: «El feminismo en la transición democrática», Revista de cultura aragonesa, $\mathrm{n}^{\mathrm{o}}$ 111-112, 2005, pp. 22-25.

López, J.: «El pregón de la fiesta» en, J. López (Coord.): Grupos marginados y Peligrosidad Social, Madrid, Campo Abierto Ediciones, 1977, pp. 7-13. 
Lorenzo, C.: Cárceles en llamas. El movimiento de presos sociales en la Transición, Barcelona, Virus Editorial, 2013.

Mapelli, M. y Grosso, M.: «La cuestión homosexual. El problema legal», El Viejo Topo, ${ }^{\circ}$ 23, Agosto, 1978, pp. 18-20.

Mesa redonda: «Homosexuales, una lucha marginal», Teoría y práctica. La lucha de clase analizada por sus protagonistas, $\mathrm{n}^{\circ} 12$, Octubre, 1977, pp. 78-87.

Mira, A.: De Sodoma a Chueca, Madrid, Egales, 2004.

Moreno, A.: «La réplica de las mujeres al franquismo», en: P. Folguera (ed.): El feminismo en España. Dos siglos de Historia, Madrid, Fundación Pablo Iglesias, 2007, pp. 123-156.

Montero, J. Mª: Anarcofeminismo en España. La Revista Mujeres Libres antes de la guerra civil, Madrid, Fundación Anselmo Lorenzo, 2003.

Moreno, A.: Mujeres en lucha. El movimiento feminista en España, Madrid, Anagrama, 1977.

Nash, M.: Mujeres libres: España 1936-1939, Barcelona, Tusquets, 1976.

Olmeda, F.: El látigo y la pluma: homosexuales en la España de Franco, Madrid, Oberon, 2004.

Pereda, R. M.: «Los grupos contra la ley de Peligrosidad Social», El País, 10 de Noviembre, 1977.

Platero, E.: «Transexualidad y agenda política: una historia de (dis)continuidades y patologización», Política y sociedad, vol. 46, nº 1 y 2, 2009, pp. 107-128.

Platero, E.: Trans*exualidades: Acompañamiento, factores de salud y recursos educativos, Barcelona, Bellaterra, 2014.

Puleo, A.: «Dos escuelas de la sospecha: hombre y mujer en el materialismo histórico y el psicoanálisis», en: A. Puleo (y otros): La Filosofía, ¿es un arma cargada de futuro?, Madrid, Publicaciones del Ministerio de Educación y Ciencia, 1993, pp. 65-82.

Puleo, A.: Dialéctica de la sexualidad. Género y sexo en la filosofía contemporánea, Madrid, Cátedra, 1992.

Quiñonero, L.: «Sueños y pesadillas de las Mujeres Libres», Viento Sur: Por una izquierda alternativa, $\mathrm{n}^{\mathrm{o}}$ 93, 2007, pp. 107-116.

Rivera, S. y Johnson, M.: STAR: Acción Travesti Callejera y Revolucionaria. Supervivencia, revuelta y lucha trans antagonista, Madrid, Ed. Imperdible, 2015.

Rubin, G: «The Traffic in Women: Notes on the 'political economy' of the sex», en: R. Reiter (ed.): Toward and anthropology of women, Monthy Review Press, Nueva YorkLondres, 1975.

Rubin, G.: «Reflexionando sobre sexo: notas para una teoría radical de la sexualidad», en: C. S. Vance (comp.): Placer y Peligro, Madrid, Revolución, 1989, pp. 113-190.

Ruiz, F. y Romero, J. (Edición a cargo de): Los partidos marxistas. Sus dirigentes, sus programas, Barcelona, Anagrama, 1977.

Sabater, A: Peligrosidad social y delincuencia, Barcelona, Nauta, 1972.

Sanfeliu, M.: «Educando y viviendo en la libertad sexual. Mujeres libres y Lucía Sánchez Saornil», en: R. Osborne (ed.): Mujeres bajo sospecha. Memoria y sexualidad, 19301980, Madrid, Fundamentos, 2012, pp. 331-345.

Scott, J: «Gender: A useful category of historical analysis», American Historical Review, vol. 91, n$^{\circ} 5,1986$, pp. 1053-1075. 
Soriano, M. A: Homosexualidad y represión. Iniciación al estudio de la homofilia, Madrid, Zero, 1978.

Soriano, M. A: «El comportamiento homosexual», Ozono, Diciembre, 1978, nº 39, pp. 46-58.

Soriano, M. A.: La marginación homosexual en la España de la Transición, Madrid, Egales, 2005.

Torres, F. (coord.): Los marginados en España, Madrid, Fundamentos, 1978.

Viladegut, P. y Solís, D.: «Todos somos bisexuales» (Entrevista con el secretario general del FAGC), El Viejo Topo, no 8, Mayo, 1977, pp. 34-35. 